\title{
A rare case of extensive idiopathic scrotal calcinosis
}

\author{
Myreddy $N^{1}$, Chaitanya $B^{2}$, Bhavani $C^{3}$, Swapna $\mathrm{SR}^{4}$ \\ ${ }^{1}$ Dr Neeraja Myreddy, MD, Professor \& HOD, ${ }^{2}$ Dr B Chaitanya, MD, Senior Resident, ${ }^{3}$ Dr C Bhavani, MD, Assistant \\ Professor, ${ }^{4}$ Dr R Sujeeva Swapna, MD, Assistant Professor, Department of Pathology, Government Medical College, \\ Anantapuramu. All are affiliated with Dr NTR University of Health sciences, Vijayawada, Andhra Pradesh, India.
}

Address for correspondence: Dr Chaitanya B, Email: bharadwaj.chaitanya@yahoo.com

\begin{abstract}
Idiopathic scrotal calcinosis (also known as "Idiopathic calcified nodules of the scrotum") is a cutaneous condition characterized by the deposition of calcium and phosphorous salts on scrotal skin. It presents as solitary or multiple, typically asymptomatic, hard yellowish intradermal nodules. Its etiology and pathogenesis are still debated. We report a case of a 30 year old male patient affected by the same with review of literature.
\end{abstract}

Key words: Calcinosis, Scrotum, Calcification

\section{Introduction}

Idiopathic scrotal calcinosis (ISC) is a rare benign disease of scrotal skin, which presents with multiple, asymptomatic nodules on the scrotum appearing in childhood or early adulthood [1]. It was first described by Lewinsky in 1883 as a subtype of calcinosis cutis [2]. It was named as "Idiopathic scrotal calcinosis" by Shapiro et al [3].

It typically begins in adolescence or early adulthood, usually during the third decade of life. The basic origin and pathogenesis remain controversial. The only treatment recommended for ISC is surgery which allows for pathologic confirmation of the disorder [4]. We present a case of this rare pathology in a 30 year old with review of literature.

\section{Case Report}

A 30 year old male presented to the General Surgery OPD with complaints of multiple, painless nodules over the scrotum of 3 months duration. The nodules progressed gradually in size and number. Mild itching was present, more during the nights.

No history of any trauma and other associated symptoms. No significant family history was present. His hematological and biochemical profile comprising complete hemogram,

Manuscript received: $10^{\text {th }}$ June 2014

Reviewed: $15^{\text {th }}$ June 2014

Author Corrected: $20^{\text {th }}$ June 2014

Accepted for Publication: $26^{\text {th }}$ June 2014 serum Calcium, Phosphorous, Alkaline phosphatase, Parathyroid Hormone and Vit D3 were normal. With a provisional diagnosis of multiple calcified sebaceous cysts, surgery was performed and the specimen comprising of the nodular lesions covered by scrotal skin was sent for HPE.

\section{Pathological findings}

Gross: The specimen measured $9 \times 5 \times 4 \mathrm{cms}$ with multiple, irregular varying size solid nodules, the cut section of which revealed multiple grey white to grey yellow flecks of calcification.

Microscopy: Microscopic examined revealed multiple, subepithelial, amorphous, basophilic deposits of varying sizes within cystic spaces.

However no epithelial lining was noted within the cysts except for the normal overlying skin epithelium. Surrounding stroma showed foreign body giant cell reaction with lymphocytic infiltrate.

A conclusive diagnosis of idiopathic scrotal calcinosis was rendered taking into account the entirely normal biochemical profile and follow up so far showed no recurrence. Images of the gross specimen and microscopy are enclosed as figure $1 \& 2$ respectively. 


\section{Discussion}

Idiopathic calcinosis cutis occurs in the absence of a tissue injury or a systemic metabolic defect. No causative factor has been identifiable. Idiopathic calcinosis of the normal skin has been described in the scrotum, penis, vulva and the breast [5]. The exact incidence of ISC is not known.

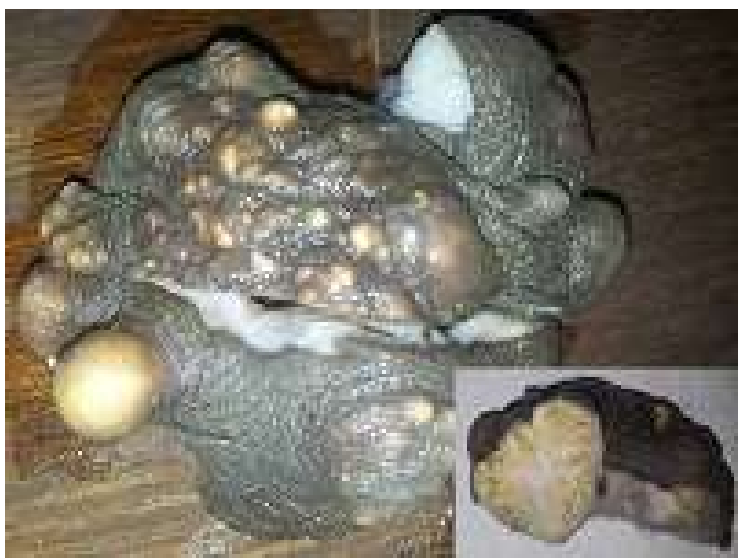

Fig 1: Gross specimen showing multiple irregular nodules with cut section showing calcifications in the inset

The etiopathogenesis of ISC is uncertain. Numerous theories in this regard have been proposed and cases have been reported periodically supporting the same. However ambiguity still remains. Some authors suggest that ISC may be due to dystrophic calcification of epidermal inclusion cysts.

This occurs following calcification of intracystic keratinous content, after a foreign body granulomatous/ mononuclear cell inflammatory response with resorption of cyst walls. This is usually a time dependent process with the oldest lesions no longer containing epithelial cells [6].

According to the findings of Veress and Feinstein, minor trauma may alter the chemical microenvironment and initiate the process $[7,8]$. Recent studies implicate dystrophic calcification of the dartos muscle following necrosis in a process similar to the calcification of the uterine leiomyoma [9]. Calcification of the scrotum in infants occur secondary to meconium peritonitis due to leakage of meconium through the processus vaginalis during the foetal life.

ISC is characterized by slow growing, firm, yellowish white nodules which vary in number. While these lesions are usually asymptomatic, some patients report itching, pain, episodes of infection and exudation of chalky white material. Unusual presentations include pedunculated forms and perineal/ suprapubic pain consistent with chronic prostatitis.

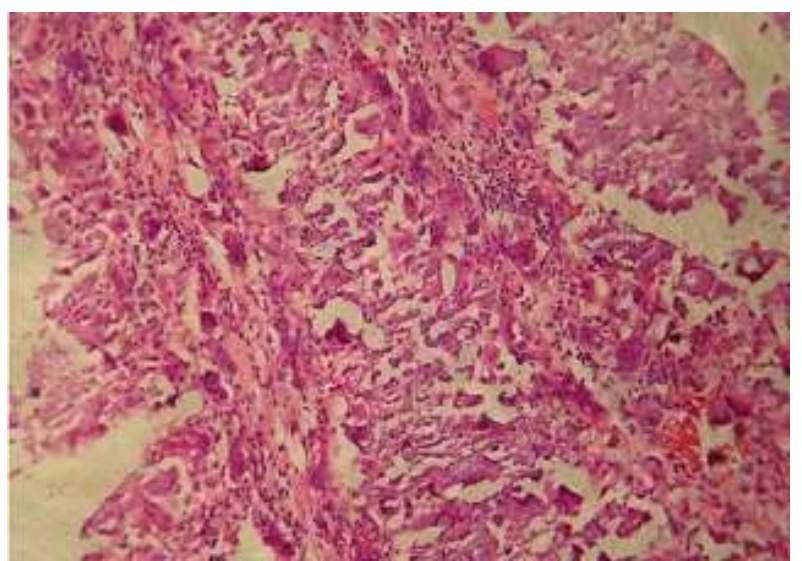

Fig 2: Microscopy showing foreign body giant cell reaction around amorphous basophilic deposits, H \& E, 100X

Histologically ISC is characterized by amorphous basophilic calcium depositions of various sizes that are surrounded by a foreign body type of giant cell reaction. Von Kossa stains the granules black. Fukaya and Ueda found numerous mast cells on toluidine blue staining in these lesions and implicated calcium chelation by mast cell secretions in the pathogenesis [10]. According to Ito et al, IHC panel of EMA, CEA and GCDPF-15 support the eccrine origin of ISC [11]. In most cases surgical en bloc excision of the scrotal skin with nodules has been found to be curative. Although recurrence is unusual, recurrent asymptomatic nodules may occur because of microscopic foci.

\section{Funding: Nil \\ Conflict of interest: Nil \\ Permission from IRB: Yes}

\section{References}

1. Michl UHG, Gross AJ, Loy V, et al. Idiopathic calcinosis of the scrotum - a specific entity of the scrotal skin. Scand J Urol Nephrol 1994; 28(2):213-217.

2. Kelten EC, Akbulut M, Colakoglu N, Bayramoglu H, Duzcan SE. Scrotal Calcinosis: is it idiopathic or dystrophic? Aegean Pathology Journal. 2005; 2(1):4-7.

3. Wright S, Navsaria H, Leigh IM. Idiopathic scrotal calcinosis is idiopathic. J Am Acad Dermatol 1991; 24(5):727-730. 
4. Khallouk A, Yasami OE, Mellas S, et al. Idiopathic Scrotal Calcinosis: A Non-Elucidated Pathogenesis and Its Surgical Treatment. Rev Urol 2011; 13(2):95-97.

5. Kanishwar VS, Waghmare RS, Puranik GV. Calcinosis Cutis in the CREST Syndrome. Bombay Hospital Journal. 2010; 52(1):108-110.

6. Song D.H, Lee K.H, Kang W.H. Idiopathic calcinosis of the scrotum: histopathologic observations of fifty-one nodules. J Am Acad Dermatol 1988; 19(6):1095-1101.

7. Veress B, Malik M, Idiopathic scrotal calcinosis. East Afr Med J 1975; 152:705-710.
8. Feinstein A, Kahana M, Levy A. Idiopathic scrotal calcinosis and vitiligo of the scrotum. J Am Acad Dermatol 1984; 11(3):519-520.

9. Gi N, Gupta AK, Sachi K, et al. Idiopathic scrotal calcinosis - a pedunculated rare variant. J Plast Reconstr Aesthet Surg 2008; 61(4):466-467.

10. Fukaya Y, Ueda H: A case of idiopathic vulvar calsinosis; The First in Japan. The Journal of Dermatology1991;18(11): 680-683.

11. Ito A, Sakamoto F, Ito M. Dystrophic scrotal calcinosis originating from benign eccrine epithelial cysts. Br J Dermatol 2001; 144(1): 146.

\section{How to cite this article?}

Myreddy N, Chaitanya B, Bhavani C, Swapna SR. A rare case of extensive idiopathic scrotal calcinosis Int J Med Res Rev 2014;2(4):379-381. doi:10.17511/ijmrr.2014.i04.19 